\title{
Defectos de la apoptosis en el linfoma cutáneo
}

\author{
Defects in apoptosis in cutaneous lymphoma
}

\author{
María Adelaida Quijano', Margarita María Velásquez² \\ 1. Médica, residente de Dermatología, Sección de Dermatología, Universidad de Antioquia, Medellín, Colombia. \\ 2. Dermatóloga, Ph.D. en Ciencias Básicas Biomédicas; docente de Dermatología, Universidad de Antioquia; Centro de Investigaciones \\ Dermatológicas, CIDERM, Sección de Dermatología, Facultad de Medicina, Universidad de Antioquia, Medellín, Colombia.
}

\section{RESUMEN}

Los linfomas cutáneos primarios se definen como linfomas no Hodgkin que se presentan en la piel, sin evidencia extracutánea de la enfermedad en el momento del diagnóstico y, como regla general, permanecen allí durante al menos seis meses. Diferentes alteraciones de las vías de la apoptosis son responsables en gran medida de la patogénesis de los linfomas cutáneos. Los enfoques terapéuticos futuros deben apuntar a restaurar la expresión del receptor de la muerte, que se deben combinar con moduladores de moléculas inhibidoras y con estimuladores de los demás mecanismos implicados en la apoptosis.

PALABRAS CLAVE: linfoma, cutáneo, células B, células T, apoptosis, vía, intrínseca, extrínseca, tratamiento.

\section{SUMMARY}

Primary cutaneous lymphomas are defined as non-Hodgkin lymphomas that occur in the skin without evidence of extracutaneous disease at diagnosis, and as a rule remain there for at least six months. Various alterations in apoptosis pathways are largely responsible for the pathogenesis of cutaneous lymphomas. Future therapeutic approaches should aim to death receptor expression, to be combined with modulators of inhibitory molecules and stimulators of other mechanisms involved in apoptosis.

KEY WORDS: Cutaneous lymphoma, B-cell, T-cell, apoptosis intrinsic pathway, extrinsic pathway, treatment.

\section{INTRODUCCIÓN}

Los linfomas cutáneos primarios se definen como linfomas no Hodgkin ${ }^{1}$ que se presentan en la piel sin evidencia extracutánea de la enfermedad en el momento del diagnóstico ${ }^{1,2} \mathrm{y}$, como regla general, permanecen allí durante al menos seis meses, mientras que los linfomas cutáneos secundarios son la manifestación cutánea de la diseminación de linfomas ganglionares o extraganglionares ${ }^{3}$. La piel es la segunda localización en frecuencia de los linfomas primarios extraganglionares, después del tubo digestivo ${ }^{1,4}$.

Los linfomas cutáneos primarios tiene una incidencia anual estimada de 1 por 100.000 casos en los países occidentales ${ }^{1}$ y son de naturaleza heterogénea, tanto clínica como histológica. En el mundo occidental, 65 a 75 \% de los linfomas cutá-

\section{Correspondencia:}

Margarita María Velásquez

Email:

mmvelasquez@yahoo.com

Recibido: 21 de mayo de 2016 Aceptado: 29 de julio de 2016

Declaramos que el contenido de esta revisión de tema no tiene conflictos de interés. Margarita María Velásquez ha participado como consultora y conferencista de Laboratorios MSD. 


\section{LINFOMA CUTÁNEO DE CÉLULAS T Y CÉLULAS NK}

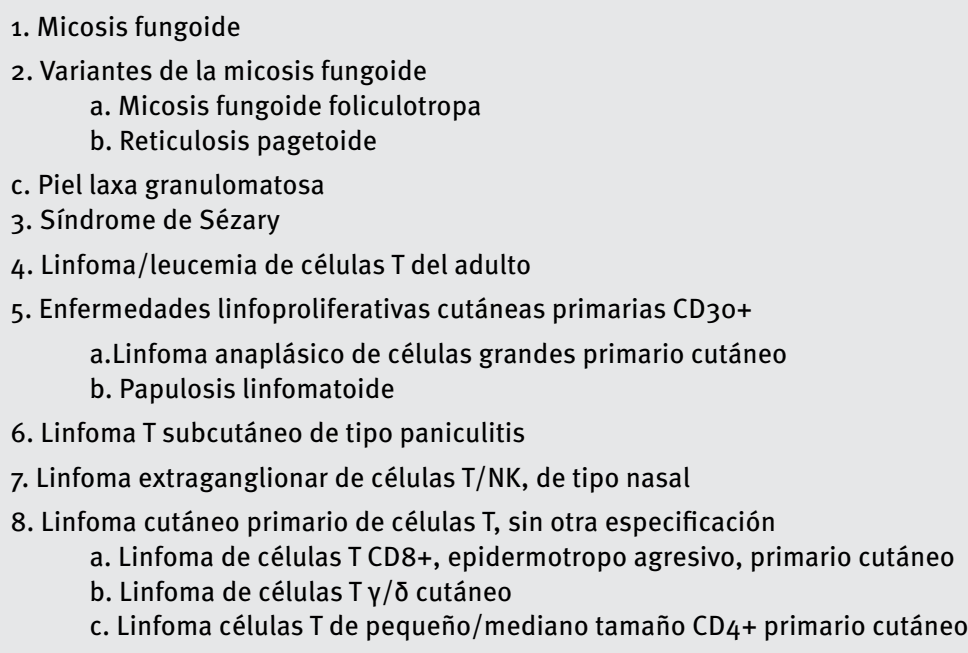

\section{LINFOMA CUTÁNEO DE CÉLULAS B}

1. Linfoma cutáneo primario de células $B$ de la zona marginal (LCCB-ZM)

2. Linfoma cutáneo primario del centro folicular (LCCB-CF)

3. Linfoma cutáneo $B$ de células grandes

a. Linfoma $B$ de células grandes tipo pierna (LCCB-tipo pierna)

b. Linfoma $B$ de células grandes intravascular

c. Otros tipos de linfoma B de células grandes

\section{NEOPLASIAS DE PRECURSORES HEMATOLÓGICOS}

Neoplasia hematodérmica CD4+/CD56+ (linfoma blástico de células NK)
TABLA 1.

Clasificación de la OMS-EORTC de los linfomas cutáneos primarios $^{6}$. neos primarios corresponden a los linfomas cutáneos de células T, de los cuales la micosis fungoide es el tipo más común, 20 a $25 \%$, a linfomas cutáneos de células $\mathrm{B}^{1,3}$, y el $10 \%$ restante pueden ser de naturaleza mixta ${ }^{3}$. Sin embargo, se han observado diferentes distribuciones en otras partes del mundo. En los países del sudeste asiático, los linfomas de células T/NK asociados a infección por el virus de Epstein-Barr son mucho más comunes que en los países occidentales, mientras que los de células B son menos frecuentes ${ }^{1}$.

Los linfomas cutáneos representan, aproximadamente, 20 distintas entidades clínico-patológicas con múltiples presentaciones clínicas, historia natural, datos histológicos, inmunofenotipos y opciones de tratamiento ${ }^{1,5-7}$. En la actualidad, los linfomas cutáneos se clasifican de acuerdo con el sistema de clasificación conjunta de la Organización Mundial de la Salud (OMS) y la European Organisation for Research and Treatment of Cancer (EORTC) ${ }^{1,5-7}$ (TABLA 1).

Según datos del Surveillance, Epidemiology and End Results Program (SEER) analizados de 1973 a 2002 20,9 incidencia del linfoma cutáneo de células $\mathrm{T}$ ajustada por edad es de 6,4 por 1'ooo.000 ${ }^{5,8,9}$ y para el de células $B$ se ha informado que es aproximadamente de 3 por $1^{\prime} 000.000^{5,8}$. En estudios epidemiológicos recientes se ha identificado un aumento constante en la incidencia de los linfomas cutáneos en los últimos decenios, en los últimos 25 años aumentó de 5 a 12,7 casos nuevos por millón de habitantes al año ${ }^{10}$, lo que podría ser resultado de un mejor diagnóstico correlacionado con un aumento real de casos, y un mejor acceso y detección por los médicos ${ }^{9,11}$, aunque hay estudios que reportan 


\section{"Se postula que en los linfomas cutáneos de células T intervienen factores genéticos, ambientales e inmunológicos".}

que este aumento se debe a factores asociados a mejoría del estado socioeconómico ${ }^{11}$.

La tasa de incidencia del linfoma cutáneo de células T aumenta con la edad, siendo muy baja antes de los 20 años (o,3 personas por millón por año), con un gran pico en el grupo de 70 a 79 años $(24,6$ por millón de personas-año). La tasa de incidencia entre varones y mujeres ha disminuido de 2,5 en 1973-1982, a 1,7 en 19932002, lo que sugiere una tendencia a ser más similar entre hombres y mujeres. Estos linfomas tienen notables diferencias de incidencia racial, con tasas mucho más altas entre los negros que entre los blancos ${ }^{11}$, quizá debido al mayor riesgo de infección por virus como el linfotrópico de células T humanas (HTLV-1) en zonas de raza negra, como el Caribe, África y el sur del Japón, donde estos virus se ven implicados como agentes etiológicos en algunos de estos casos ${ }^{12}$.

Los linfomas cutáneos de células $\mathrm{B}$ más comunes son: el de células B difuso (40,1\%), el centrofolicular (30,0 \%) y el de células B de la zona marginal $(24,8 \%)$. La tasa anual de incidencia de linfoma cutáneo de células B es casi el doble en los hombres (4,0 por 1́ooo.00oo), en comparación con las mujeres (2,3 por $1^{\prime}$ ooo.00o) ${ }^{9}$. El de células $\mathrm{B}$ y el de células $\mathrm{T}$ difieren en su distribución entre razas y grupos étnicos; los primeros se encuentran más comúnmente en los blancos no hispanos (3,5 por millón de personas al año), que en los negros (1,5 por millón de personas al año) ${ }^{11}$. La edad media en el momento del diagnóstico, en los hombres, fue de 61,3 años y, en las mujeres, de 65,6 años $(p=0.0001)^{8}$.

\section{MICOSIS FUNGOIDE}

La micosis fungoide es el linfoma cutáneo de células T más común, $76 \%$ \%,8,9. Es un linfoma producido por la expansión clonal de células T, en la mayoría de los casos CD4 de memoria, en la piel. Clínicamente, la micosis fungoide se presenta más comúnmente con parches indoloros que, si no se tratan, pueden progresar a placas induradas y, en última instancia, podrían llegar a tumores o a eritrodermia ${ }^{5}$. Tiene una tasas de incidencia de 1.400 casos por año, y 4,5 a 5 por millón de personas están afectadas ${ }^{1,2,8}$; la incidencia por millón de personas según el sexo es de 5,6 para hombres y de 3,6 para mujeres ${ }^{8}$. Se ha reportado un aumento de la incidencia en los últimos 30 años de, al menos, 2,9 casos por millón por década 9 . Entre los factores de riesgo para el desarrollo de micosis fungoide, se incluyen la edad avanzada, la raza negra y el sexo masculino ${ }^{5,9}$. Los grupos raciales diferentes a los blancos presentan micosis fungoide a una edad más temprana y los afroamericanos tienen mayor riesgo de presentar la enfermedad en estadios más avanzados, tumores y eritrodermia ${ }^{9}$.

La edad media de diagnóstico de la micosis fungoide es mayor en hombres (58,6 años) que en mujeres $(55,4)(p=0,0005)^{8}$.

\section{ETIOPATOGÉNESIS}

Se postula que en los linfomas cutáneos de células T intervienen factores genéticos, ambientales e inmunológicos. Algunos hallazgos indican anormalidades genéticas en algunos genes supresores de tumores, como p53, deleciones e inserciones, y una posible relación con algunos alelos del HLA de clase II asociados a los casos de micosis fungoide familiar, y en general, se considera que la hipótesis de estimulación antigénica persistente de antígenos aún no identificados es la más aceptada a la fecha.

Entre los factores ambientales, la exposición ocupacional a hidrocarburos aromáticos halogenados, $\mathrm{y}$ el trabajo en la industria del papel, el vidrio, la cerámica y la metalmecánica, entre otras, también se 
han encontrado relacionados ${ }^{5,9,13}$, pero esto aún no es concluyente ${ }^{7}$.

También, se han cuestionado agentes infecciosos como causantes de este linfoma de células $\mathrm{T}$, como es la infección latente por citomegalovirus ${ }^{9}$, que puede desempeñar un papel en la propensión a la micosis fungoide en sujetos predispuestos a la inducción de proliferación de células $\mathrm{T}$ y resistencia a la apoptosis ${ }^{5,14,15}$, y el síndrome de Sézary, en el cual el estado de inmunosupresión puede ser responsable de la reactivación de este virus que, a su vez, puede interferir con la evolución de la enfermedad ${ }^{15}$. Se ha encontrado seropositividad para citomegalovirus hasta en $97 \%$ de los paciente con micosis fungoide y sindrome de Sézary en estadios avanzados ${ }^{16}$. Además, se ha sugerido que el HTLV-1 puede estar implicado en la transformación neoplásica de las células T CD4, ${ }^{9,17,18}$, sobre todo para la variante linfoma/leucemia de células T del adulto ${ }^{12}$. En otros estudios se ha evaluado la infección por el virus de Epstein-Baar. La asociación con agentes infecciosos se ha estudiado parcialmente, pero los hallazgos no son constantes en todas las poblaciones estudiadas ${ }^{9,19}$.

Se han registrado cambios en el número de un supresor de tumores y en los genes relacionados con la apoptosis en pacientes con micosis fungoide y el síndrome de Sézary, aunque aún no está claro si la mayoría de estas alteraciones afectan el comportamiento de las células T. En 50 a $85 \%$ de los pacientes con estos trastornos, una frecuente anormalidad genética parece interferir con la expresión de $\mathrm{NAV}_{3}$. Generalmente, las mutaciones en los genes p53, p15, p16, JunB y PTEN se encuentran en la enfermedad en etapa avanzada, lo que sugiere que son eventos genéticos secundarios y no forman parte del inicio de la enfermedad. Además, también se ha reportado pérdida de las vías de apoptosis normal de las células T, incluyendo disminución o ausencia de la expresión de Fas Ligando, 9,16,20,21.

Aunque se han realizado avances en el conocimiento de la genética molecular de los linfomas cutáneos de células $B$, los mecanismos relacionados con la presencia y persistencia de células B malignas en la dermis permanecen desconocidos. En la actualidad, no se han identificado lesiones moleculares específicas en estos linfomas ${ }^{22}$, ni translocaciones cromosómicas de la activación de proto-oncogenes vistas en los linfomas no Hodgkin ganglionares y extraganglionares, como la ruptura de la doble hélice de ADN durante la recombinación $\mathrm{V}(\mathrm{D}) \mathrm{J}^{22,23}$.

En varios informes se especula sobre el papel de factores infecciosos, inmunológicos, cromosómicos y genéticos en la aparición de los linfomas cutáneos de células $\mathrm{B}^{23}$. Algunos casos se han relacionado con una estimulación antigénica persistente, secundaria a agentes infecciosos como algunos virus (virus del herpes humano de tipo 8 [HHV-8], virus de la inmunodeficiencia humana [HIV], virus de la hepatitis C [VHC], virus linfotrópico de células T humanas [HTLV-1]) o bacterias (Borrelia burgdorferi) ${ }^{22-24}$, aunque la asociación entre Borrelia y el linfoma de células B se describe en algunas poblaciones europeas, no ha sido encontrada en poblaciones americanas ${ }^{23}$.

En un estudio se logró demostrar la presencia de secuencias específicas de ADN del HHV-8 en un porcentaje de pacientes con diferentes tipos de linfomas cutáneos primarios de células B, planteándose la posible implicación de este virus linfotrópico en la patogénesis de algunos de estos casos. Sin embargo, se ha demostrado el genoma del HHV-8 en el 5 a $10 \%$ de la población sana en ciertas zonas geográficas, lo cual sugiere la posibilidad de que la positividad del HHV-8 represente un epifenómeno. Por lo tanto, son necesarios más estudios para evaluar el papel del HHV-8 en la patogénesis de las enfermedades linfoproliferativas cutáneas ${ }^{25}$.

También, se ha descrito la asociación de linfomas B y enfermedades autoinmunitarias (síndrome de Sjögren, tiroiditis autoinmunitaria, anemia hemolítica autoinmunitaria, lupus eritematoso sistémico), aunque en los linfomas cutáneos de células B hay poca evidencia significativa que pueda establecer una relación de causalidad $^{22-24}$. En otros estudios se han descrito reordenamientos de los genes $b c l-1, b c l-2$ y $b c l-6$ reguladores de la apoptosis y en algunos genes supresores tumorales ${ }^{23}$.

\section{APOPTOSIS}

La apoptosis es un proceso activo que conduce a la muerte celular, para mantener la normalidad de proceso fisiológicos, como son la propia organización funcional en el sistema inmunitario, en el sistema nervioso central, los cambios morfogenéticos durante el desarrollo embrionario y la eliminación de células dañadas ${ }^{26}$, y es necesaria para la homeostasis celular, como en el caso de los linfocitos, en el cual, después de estímulos para su proliferación, se devuelven las poblaciones de células $\mathrm{T}$ y $\mathrm{B}$ a sus concentraciones adecuadas ${ }^{27,28}$ mediante la muerte celular inducida por activación. En la defensa contra el cáncer, sirve como un mecanismo de protección eficiente que elimina células mutadas o infectadas por virus, que puedan tener la capacidad de desarrollar el cáncer ${ }^{29}$.

La apoptosis es un proceso activo mediado por diferentes vías de señalización ${ }^{26,27}$, pero en todos los casos, la muerte real de la célula implica la activación de un 


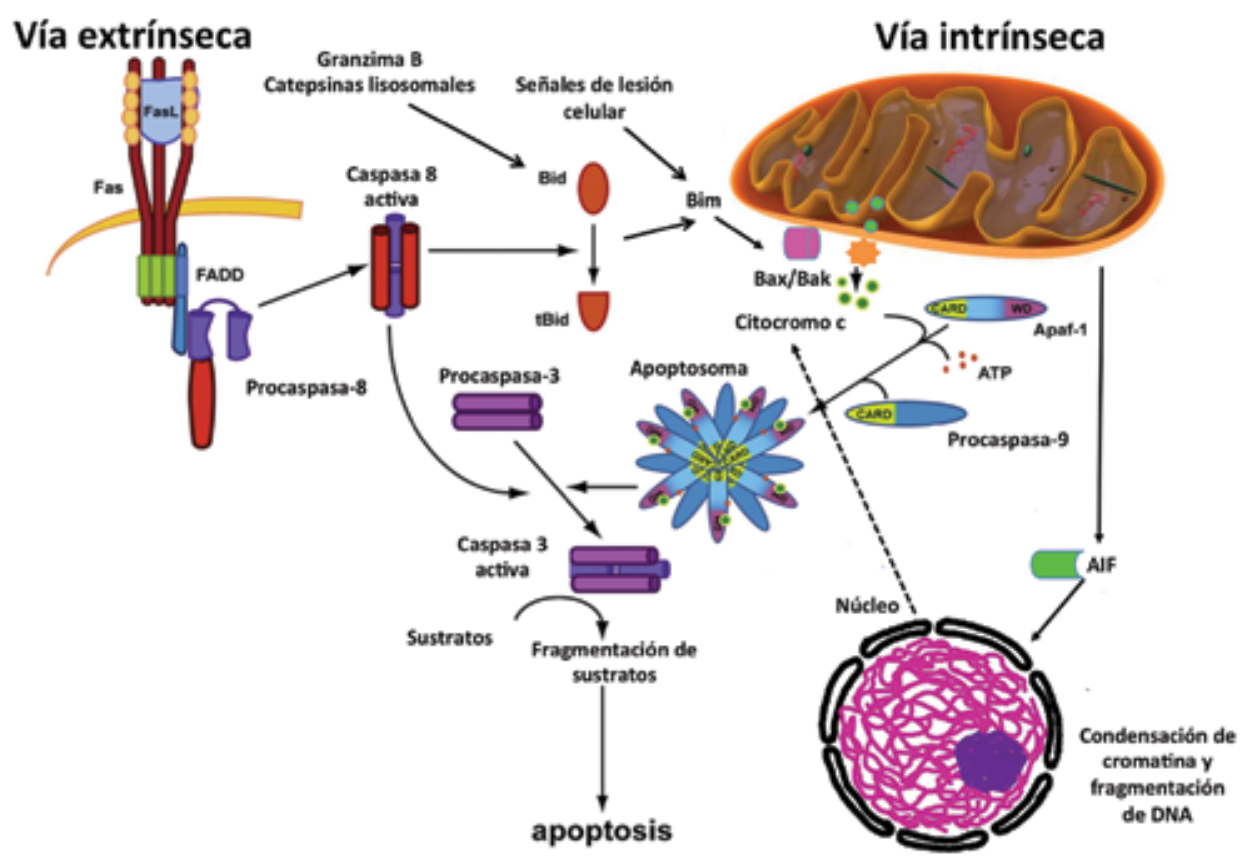

FigURA 1. Vía extrínseca e intrínseca de la apoptosis.

En la vía extrínseca de la apoptosis intervienen receptores de membrana, miembros de la familia de receptores del factor de necrosis tumoral (TNF), entre estos, Fas y su ligando, FasL. Luego de la unión Fas a FasL, se recluta la proteína adaptadora FADD y esta se asocia con la procaspasa-8. Después de esto, se forma un complejo y se activa la procaspasa-8 lo que da lugar al inicio de la apoptosis. Las caspasas activan endonucleasas que degradan material nuclear y otras proteasas que lisan proteínas nucleares y el citoesqueleto. Las caspasas 3, caspasas 6 y caspasas 7 funcionan como efectoras. La apoptosis mediada por la vía extrínseca se puede inhibir por la proteína c-FLIP.

La vía intrínseca degenera por daño en el ADN, limitación de factores de crecimiento, estrés oxidativo, aumento en el calcio del citosol o estrés celular. En este proceso se reduce el potencial de membrana mitocondrial y se libera citocromo C y Apaf-1, los cuales se unen a la procaspasa 9 para formar el apoptosoma, el cual activa a la caspasa 9 y esta a su vez activa a las caspasas 3 y 7 , efectoras del daño celular.

grupo de proteasas llamadas caspasas (proteasa de cisteína con especificidad por residuos de ácido aspártico). Cada célula del cuerpo produce caspasas, por lo que cada célula tiene el potencial de inducir su propia muerte, pero, estas caspasas están en forma inactiva y se activan en la célula al recibir señales apropiadas para la muerte $\mathrm{e}^{27}$.

Las alteraciones en la apoptosis están involucradas en la patogénesis de varias enfermedades como el cáncer, el sida, otros trastornos del sistema inmunitario, enfermedades cardiovasculares, y muchas enfermedades neurodegenerativas (enfermedad de Alzheimer, enfermedad de Parkinson, enfermedad cerebral isquémica y hemorrágica); también, se han descrito en los linfomas cutáneos. Por lo tanto, el estudio de la apoptosis es importante, no sólo para entender los mecanismos de regulación de los procesos fisiológicos normales, sino también, para estudiar los mecanismos fisiopatológicos de muchas enfermedades humanas ${ }^{26,29}$.

Existen dos vías principales de apoptosis en varios tipos celulares y los linfocitos $\mathrm{T}$ utilizan ambas vías (FIGURA 1). 


\section{Vía del receptor mortal o extrínseca}

Cuando las células $\mathrm{T}$ son activadas, expresan en su superficie dos proteínas relacionadas con la muerte celular, Fas/CD95 y ligando Fas (FasL) ${ }^{29}$. Estas proteínas son miembros de la familia de receptores o ligandos del factor de necrosis tumoral (TNF) y su ligando (TNFR); por lo tanto, el TNF también puede interactuar en la inducción de la apoptosis ${ }^{26,27}$. Cuando el receptor Fas se une al FasL, hay un cambio estructural y se forma un complejo homotrimérico de los receptores de ligando entrelazados que potencia la interacción con los dominios de muerte: FADD (Fas Associated via Death Domain) ${ }^{26,29}$. A esto le sigue la incorporación de la procaspasa 8 (forma inactiva de la caspasa 8) y esta unión de FADD con la procaspasa 8 ocasiona la escisión proteolítica de la procaspasa 8 hasta llegar a su forma activa, la caspasa $8^{26,273^{\circ}}$. Esta se encarga de escindir la procaspasa 3 y así producir caspasa 3 activa, que es la que inicia la fase de ejecución de la apoptosis por proteólisis de sustratos que llevan a la célula a la muerte $\mathrm{e}^{26,27,31,32}$.

La caspasa 8 también se puede unir a una proteína citoplásmica llamada Bid, lo que genera un fragmento de Bid, que puede activar la vía mitocondrial (que se explica más adelante) mediante una caspasa ${ }^{27,29,31,32}$. Se ha descrito que Bid también puede ser activada por la proteasa citotóxica de linfocitos granzima B y ciertas catepsinas lisosómicas ${ }^{31}$.

\section{Vía mitocondrial o intrínseca}

La vía mitocondrial está regulada por proteínas de la familia del Bcl2, de la cual hay tres grupos: las del grupo I (Bcl-2 y Bcl-XL) son antiapoptóticas, y las del grupo II (Bax y Bak) y las del grupo III (Bim y Bid) son proapoptóticas $^{27,30,33}$. Estas proteínas proapoptóticas son inducidas y activadas por señales de lesión celular (deficiencia del factor de crecimiento y señales de supervivencia, lesión del ADN, mal plegamiento de proteínas). Bim es considerado el detector de estrés celular más importante y cuando es activado se une a dos proteínas efectoras proapoptóticas, Bax y Bak, que se oligomerizan y se insertan en la membrana mitocondrial externa, lo cual aumenta su permeabilidad ${ }^{30}$ y favorece la salida del citocromo c al citoplasma. Este se une al factor 1 activador de la proteasa apoptótica, APAF1 (Apoptotic Protease Activating Factor 1) y se genera un cambio en la conformación por oligomerización de APAF1 mediado por dATP o ATP26,31. Entonces, la procaspasa 9 se une a los oligómeros de APAF1 y se forma una molécula grande y compleja llamada apoptosoma $^{27,31}$. La caspasa 9 genera proteólisis de la procaspasa 3 y resulta la caspasa 3 activa, la cual conduce a la fragmentación del ADN nuclear y algunos cambios celulares que inducen la muerte celular ${ }^{30,32}$.

El factor inductor de apoptosis, AIF (Apoptosis Inducing Factor), también es liberado por las mitocondrias durante este proceso ${ }^{27,31}$; pasa al citoplasma y al núcleo, donde condensa la cromatina y fragmenta el ADN a gran escala mediante mecanismos desconocidos, aumenta la liberación de citocromo $\mathrm{C}$ y potencia, así, la apoptosis. Este factor induce apoptosis independiente de caspasas $^{26}$.

La p53 es una proteína celular supresora de tumores, implicada en la protección de la integridad del genoma, la inducción de la apoptosis, la regulación de la glucólisis y la autofagia, incluso la promoción de la diferenciación celular. La señalización mediada por la activación de la p53 se produce como reacción a una amplia gama de factores de estrés, intrínsecos y extrínsecos, de la célula ${ }^{32}$. La proteína p53 se relaciona en la activación de diferentes componentes de las vías apoptóticas. Tiene la capacidad de activar la transcripción de diversos genes proapoptóticos $\mathrm{y}$, también, puede desencadenar la apoptosis por represión de los genes antiapoptóticos, promoviendo así la activación de las caspasas. En la mitocondria, forma un complejo con la ciclofilina D que conduce a la interrupción de la estructura mitocondrial, facilitando así la liberación del citocromo C. Además, está implicada en la activación del apoptosoma mediante la inducción de la expresión de $\mathrm{APAF}^{32,3536}$.

También, la p53 puede activar la vía extrínseca de la apoptosis al estimular la transcripción del receptor Fas, y la sobreexpresión de la p53 puede mejorar los niveles de del receptor Fas en la superficie celular. Además, la p53 puede regular la transcripción de la proteína Bid, que tiene la capacidad única para conectar la vía extrínseca con la intrínseca ${ }^{32}$.

\section{DEFECTOS DE LA APOPTOSIS EN EL LINFOMA CUTÁNEO}

Como se describió anteriormente, los linfomas cutáneos de células $\mathrm{T}$ se caracterizan por la proliferación clonal de linfocitos $\mathrm{T}$ maduros en la piel $\mathrm{y}$, debido al bajo potencial de replicación de sus células, se sugiere que más de una proliferación celular es una acumulación y puede ser el resultado de una regula- 
ción defectuosa de la apoptosis de las células $\mathrm{T}^{28,37,38}$.

La resistencia a la apoptosis es un mecanismo implicado en la génesis de varios tipos de tumores, con una disminución o pérdida de la expresión del receptor Fas en la superficie celular, en comparación con la observada en las células no tumorales ${ }^{37}$. Se ha evidenciado que las mutaciones del gen $\mathrm{Fas}^{38}$ conduce a defectos de señalización en Fas/FasL que puede conducir a la eliminación incompleta de células autorreactivas y resultar en trastornos linfroproliferativos y el síndrome similar al lupus en ratón, como se observó en las cepas de ratones con mutación en el gen del receptor FAS, $\operatorname{lpr}$ y $\operatorname{lpr}^{c g} 39,4^{\circ}$.

La resistencia a la apoptosis también puede producirse por la expresión anormal de los inhibidores intracelulares de la apoptosis, como cFLIP, o proteína inhibidora de la enzima FLICE (FADD-like IL-1betaconverting enzyme $)^{41}$, la cual es muy similar a las caspasas 8 y 10, y compite con la procaspasa 8 para su unión al dominio $\mathrm{FADD}^{28,37}$. Por lo tanto, la sobreexpresión de cFLIP y las deficiencias en la señalización del receptor Fas, se asocian a la inhibición de la apoptosis en el linfoma cutáneo de células $\mathrm{T}^{28,42}$. Esto se ha visto en modelos animales, en los cuales se inyectan ratones inmunocompetentes con cepas de células de linfoma $\mathrm{B}$ de múrido (A20) transducidas con KSHV-FLIP (proteína del virus del herpes humano de tipo 8 asociado a sarcoma de Kaposi, miembro de la familia del cFLIP), para sobreexpresar el cFLIP, lo cual implica bloqueo de la apoptosis, generando aumento de la progresión y la agresividad del tumor ${ }^{40-43}$.

En los linfomas cutáneos de células B, sobre todo en la variante folicular, se ha observado una sobreexpresión de la proteína antiapoptótica $\mathrm{Bcl} 2$, lo que genera acumulación de las células B. Algunos autores afirman que en los linfomas cutáneos de células $\mathrm{T}$ ya se ha analizado la Bcl2 mediante biología molecular, pero no se ha encontrado ninguna anormalidad ${ }^{29,44}$. Aunque en un estudio para evaluar la expresión de la $\mathrm{Bcl} 2$ después de la terapia PUVA para micosis fungoide reportaron una ligera disminución en la expresión de Bcl-2 en los linfocitos del paciente, esto no es algo concluyente, ya que con los resultados se dedujo que la apoptosis inducida por PUVA no se debía a disminución de la Bcl-2, pues no hubo diferencia significativa entre sus niveles antes y después de la administración de la terapia $(p=0,3)^{45}$. En otro estudio se reportó una sobreexpresión de proteínas antiapoptóticas como la Bcl-2, en las células del linfoma cutáneo de células $\mathrm{T}^{46}$.

$\mathrm{Al}$ parecer, en el año 2000 se reportó por primera vez la disminución en la expresión del receptor Fas en los linfocitos $\mathrm{CD}_{4}+$, en un estudio en el que se compararon
20 pacientes con linfoma cutáneo de células T (16 con micosis fungoide y 4 con síndrome de Sézary) con un grupo de 25 pacientes con lesiones inflamatorias benignas, como psoriasis y eccema agudo y subagudo, y con un segundo grupo control de 15 pacientes con úlceras varicosas en los miembros inferiores, considerados como "controles sanos". A todos se les determinó el fenotipo de linfocitos con inmunofluorescencia directa, y las poblaciones y subpoblaciones de linfocitos se analizaron por citometría de flujo ${ }^{44}$. En este estudio se logró demostrar que la expresión del receptor Fas/ CD95 en los linfocitos CD4+ circulantes fue menor en los pacientes con linfoma cutáneo de células T al compararlo con los controles (11,7 \% en linfoma cutáneo de células T Vs. 16,7 \% en lesiones inflamatorias benignas Vs. 13,2 \% en "controles sanos”). Además, se encontró que la expresión del receptor Fas/CD95 parecía seguir la evolución clínica de los algunos pacientes, con incremento de su expresión durante la remisión seguido de una disminución durante la recaída ${ }^{44}$. En otros estudios en el 2009 se demostró que la deficiencia del receptor FAS es un mecanismo molecular adquirido responsable de la resistencia a la apoptosis en el linfoma cutáneo de células T e indican que la regulación positiva de la expresión de este receptor puede restaurar la sensibilidad a la apoptosis ${ }^{47}$.

En otro estudio en pacientes con linfomas cutáneos de células $\mathrm{T}$ (micosis fungoide, LCCT CD30+ y LCCT CD30-), se encontró que la pérdida del receptor Fas se observaba en los linfomas agresivos, pero no en aquellos de progresión lenta. Por lo tanto, sugirieron que la pérdida de la expresión del receptor Fas puede ser uno de los mecanismos que permiten a las células tumorales escapar de una reacción inmunitaria efectiva y pueden contribuir al pronóstico desfavorable de algunos tipos de linfomas cutáneos de células T. Por ejemplo, en el grupo de $\mathrm{CD}_{30}+$, que incluye la papulosis linfomatoide y el LTCL CD30+ cutáneo primario, se demostró un aumento en la expresión del receptor Fas, lo que podría explicar su tendencia a desaparecer espontáneamente y rara vez tener manifestaciones extracutáneas, con un excelente pronóstico y una supervivencia del $90 \%$ a los cinco años. Por el contrario, los linfomas de células T CD30- generalmente tiene un mal pronóstico, con una supervivencia de $25 \%$ a los cinco años, al parecer por la baja expresión encontrada del receptor Fas, aunque los mecanismos moleculares y genéticos subyacentes a las diferencias en el comportamiento clínico entre estos grupos de linfomas cutáneos de células T son en gran parte desconocidos ${ }^{43,48}$.

No obstante, la pérdida de la expresión del receptor Fas no es el único mecanismo por el cual las células 


\section{"La sobreexpresión de cFLIP y las deficiencias en la señalización del receptor Fas, se asocian a la inhibición de la apoptosis en el linfoma cutáneo de células T"}

se vuelven resistentes a la muerte celular mediada por Fas; en un estudio se reporta que el $31 \%$ de los pacientes con síndrome de Sézary eran resistentes a FasL, a pesar de la adecuada expresión del receptor Fas en su superficie celular. En estos casos, podría haber aumento de la expresión del cFLIP 37.

Hasta ahora no están claros los mecanismos de disminución o pérdida de la expresión del receptor Fas en las células de los linfomas cutáneos de células T, pero, en un estudio del 2010 en pacientes con síndrome de Sézary, se demostró que la disminución de la expresión del receptor Fas se atribuye a una hipermetilación en la zona $\mathrm{CpG}$ de Fas y no a mutaciones funcionales dentro de la región transcrita de Fas. Esto mismo fue reportado en un estudio del 2011, que no solo incluía pacientes con síndrome de Sézary, sino otras variantes de linfoma cutáneo de células T; se encontró una relación inversa entre la metilación del promotor del gen del receptor Fas y la expresión de las proteína Fas ${ }^{49}$.

Esta misma hipermetilación del promotor del gen del receptor Fas se ha descrito en cáncer de colon y de próstata, y en el carcinoma pulmonar de células pequeñas; por esto es que los inhibidores de la histona deacetilasa (inhibidores HDAC) ${ }^{50-52}$, como vorinostat y romidepsin, revierten algunas de las alteraciones epigenéticas asociadas con cáncer, lo que resulta en una nueva expresión de los genes silenciados que están implicados en la detención del crecimiento, la diferenciación terminal o la apoptosis en células de carcinoma ${ }^{52}$.

En un estudio del 2003 se demostró que las proteínas Bcl-XL, Bax y Bak se expresan en las líneas celulares del linfoma cutáneo de células T. Esto sugiere que hay un equilibrio entre los inductores de la apoptosis y los protectores de la apoptosis, pero, en este estudio, con anticuerpos específicos de fosforilación, se demostró que la proteína Bak es inactivada, al menos parcialmente, por la fosforilación de la serina en una posición específica en el linfoma cutáneo de células T. La fosforilación de la Bak puede ocurrir en etapas posteriores de la enfermedad ${ }^{33}$.

En un estudio de 2011, se encontró que el supresor tumoral p53 se encuentra no funcional en las células de pacientes con síndrome de Sézary, alterando así la inducción de apoptosis ${ }^{53}$. En otro, del 2012, se reportó que las mutaciones de la proteína p53 en pacientes con micosis fungoide y con linfomas $\mathrm{CD}_{3}+$ son raras, de $2 \%$ y $5 \%$, respectivamente. No obstante, en 75 a $80 \%$ de los pacientes con síndrome de Sézary, se ha observado una deleción focal en 17p13.3-17p13.1 que conduce a la pérdida de la expresión de la proteína $\mathrm{p} 53^{36}$.

Los pacientes con síndrome de Sézary presentan en sus células una deficiente expresión de la proteína SATB1 (Special AT-rich region Binding protein 1), reguladora clave del desarrollo de las células $\mathrm{T}$ y de $\mathrm{su}$ maduración. Este defecto en la expresión de SATB1 contribuye a la resistencia de la muerte celular inducida por activación mediante regulación de la transcripción de FASL ${ }^{54,55}$. Además, se ha visto una correlación entre la expresión nuclear de STAB1 y un mejor curso clínico de la enfermedad, lo cual se refleja por una progresión más lenta o ausencia de progresión a una etapa más avanzada ${ }^{55}$.

El NFкB (Nuclear factor $\kappa$ B) es un factor de transcripción central para la generación de reacciones inmunitarias e inflamatorias, la regulación del ciclo celular y la protección contra apoptosis. Se ha demostrado que 
la activación constitutiva del NFKB está involucrada en la supervivencia y la resistencia a la apoptosis de las células T malignas en los linfomas cutáneos de células $\mathrm{T}$, lo cual sugiere que la inhibición de la activación constitutiva de NF-kappa B induce la apoptosis en las células $\mathrm{T}^{56,57}$. Por esto, se ha trabajado en fármacos inhibidores como el bortezomib, el cual ejerce efectos antitumorales in vitro en el linfoma cutáneo de células $\mathrm{T}^{56}$. Sin embargo, el mecanismo molecular que subyace esta activación permanece sin resolverse hasta ahora. No obstante, se sugiere que la cinasa IKK2 (cinasa en-

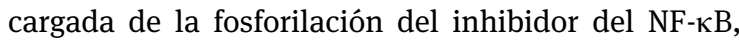

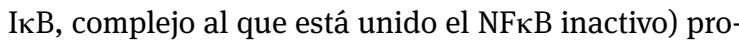
porciona una clave para la activación constitutiva del NFкB en el linfoma cutáneo de células T y promueve la supervivencia de estas neoplasias malignas ${ }^{57}$.

$\mathrm{Ku}$ es una proteína heterodimérica de dos subunidades, Ku70 y Ku8o. Ku70 es un inhibidor de la apoptosis que pertenece a la familia Bcl-2. Inhibe la apoptosis mediante el bloqueo de la translocación del proapoptótico Bax a la mitocondria y esto se produce de forma independiente de la Ku8o.

Se ha demostrado que $\mathrm{Ku} 7 \mathrm{o} / 80$ es un componente crítico de la reparación del ADN de doble cadena y el inhibidor clave de la apoptosis, y que se reduce de manera significativa en las células $\mathrm{T}$ de las lesiones infiltrantes del linfoma cutáneo de células $\mathrm{T}$, en comparación con los linfocitos normales de la piel. Además, se encontró que la disminución de la concentración de $\mathrm{Ku} 7 \mathrm{O} / 80$ en las células T no es una característica de la psoriasis y la dermatitis de contacto, lo cual sugiere que la disminución de la expresión de $\mathrm{Ku} 7 \mathrm{O} / 80$ en las lesiones del linfoma cutáneo de células T no es secundaria a un medio de citocinas inflamatorias, sino, más bien, una característica de las células T malignas o el microambiente cutáneo en el linfoma cutáneo de células T. En esto existe una paradoja, pues las células T clonales del linfoma cutáneo de células $\mathrm{T}$ tienen una resistencia inicial a la apoptosis, aunque son sensibles a las terapias inductoras de apoptosis; por lo tanto, la disminución de la expresión de Ku7o puede influir de manera positiva en la reacción al tratamiento ${ }^{58}$.

\section{APOPTOSIS Y NUEVOS TRATAMIENTOS}

Las decisiones terapéuticas para los linfomas cutáneos de células $\mathrm{T}$ se basan en el estadio temprano o tardío de la enfermedad: estadios IA a IIA o estadios IIB a IVB. El tratamiento debe proteger la función inmunitaria para prevenir el colapso inmunológico, ya que inicialmente se observó que los tratamientos agresivos en etapas tempranas predisponían a recidivas rápidas y mayor morbilidad y mortalidad asociadas al tratamiento ${ }^{59}$. No hay cura para el linfoma cutáneo de células T, por lo que el énfasis del tratamiento está en suprimir o mejorar las lesiones para producir remisión de la enfermedad. Esto tiene como objetivo mejorar la calidad de vida, y optimizar el tiempo libre de enfermedad y la supervivencia global $^{60}$.

Los esfuerzos de las investigación actuales se concentran en una mejor comprensión de la resistencia a la quimioterapia en el linfoma cutáneo de células T avanzado, y las nuevas estrategias terapéuticas están enfocadas en tratar de revertir la resistencia a la apoptosis actuando en las diferentes puntos implicados ${ }^{36}$.

Entre las novedades se encuentran los inhibidores de las deacetilasas de histona (histone deacetylases, HDAC) $)^{50-52}$, como el vorinostat y el romidepsin, que revierten algunas de las alteraciones epigenéticas asociadas con el cáncer, lo que resulta en la nueva expresión de los genes silenciados que están implicados en la detención del crecimiento, la diferenciación terminal o la apoptosis en las células del carcinoma ${ }^{52}$. El vorinostat (suberoilanilida del ácido hidroxámico, SAHA) ha sido aprobado para el tratamiento del linfoma cutáneo de células $\mathrm{T}$ y actúa como un regulador negativo del cFLIP, induciendo la apoptosis en el linfoma cutáneo de células $\mathrm{T}^{61}$.

En estudio se encuentra el fármaco Nutlin-3a, que se ha destacado como una herramienta prometedora para estabilizar y activar la proteína celular supresora de tumores p53, y así, inducir la apoptosis ${ }^{36}$.

El avicin D inhibe la activación del factor STAT3 (Signal Transducer and Activator of Transcription 3) y disminuye los antiapoptóticos Bcl-2 y survivin en el linfoma cutáneo de células $\mathrm{T}$, teniendo potencial efecto terapéutico en pacientes con el síndrome de Sézary ${ }^{62}$.

Hay estudios que sugieren que la curcumina induce selectivamente la apoptosis en asociación con una baja regulación de las vías de señalización de STAT3 y NFkB en las células de los linfomas cutáneos de células T. Esto fundamentaría su uso potencial como un agente terapéutico linfoma cutáneo ${ }^{63}$.

La decisión sobre cuál tratamiento se debe usar para los linfomas cutáneos de células B depende en gran medida de la clasificación histológica, el número, la extensión y la localización de los infiltrados, así como de la edad y el estado funcional del paciente ${ }^{24,64}$. Se consideran factores pronósticos la localización anatómica, la morfología de célula redonda y la multi- 
plicidad de las lesiones, aunque este último factor no ha sido demostrado ${ }^{23}$. Sin embargo, el pronóstico depende fundamentalmente de la presencia de afectación extracutánea ${ }^{22}$.

En linfomas cutáneos de células B con lesiones únicas o localizadas, el tratamiento de elección es la cirugía, la radioterapia o ambas ${ }^{22-24,65}$, aunque se desconocen las ventajas de la radioterapia sobre la cirugía en las lesiones localizadas de pequeño tamaño $0^{23}$; en tumores múltiples o recidivantes, se recurrirá a la quimioterapia, idealmente poliquimioterapia CHOP: ciclofosfamida, adriamicina, vincristina y prednisona, ya que ha demostrado menores recidivas en comparación con los esquemas sin antraciclinas ${ }^{23,24}$.

En estudios recientes se ha propuesto la monoterapia con rituximab, anticuerpo monoclonal quimérico anti$\mathrm{CD} 20$, para uso intravenoso e intralesional con buenas tasas de mejoría en los linfomas B de curso lento, en los linfomas cutáneos de células $\mathrm{B}$ de la zona marginal (LCCB-ZM), el del centro folicular (LCCB-CF) y el de células $B$ de las piernas. Esta sustancia reduce eficazmente el recuento de células $B$ circulantes en pacientes con linfoma ${ }^{22-24,64-66}$. El rituximab ha demostrado inducir la destrucción de las células B del linfoma, independientemente del sistema del complemento, y lo hace mediante citotoxicidad mediada por anticuerpos, activación del complemento e inducción directa de la apoptosis. También, es capaz de sensibilizar las células a los efectos citotóxicos de otros antineoplásicos ${ }^{64,65}$. El $85 \%$ de los LCCB tipo pierna tienen sobreexpresión de la proteína bcl-2 (factor de peor pronóstico), por lo que se sugiere añadir rituximab a las poliquimioterapias con antraciclinas, ya que esta actúa también por la vía de la proteína bcl-2 $2^{65}$. Aunque su uso no es de primera elección, es necesario considerarlo en lesiones múltiples o recidivantes, o en lesiones en localizaciones visibles donde la radioterapia o la cirugía puedan dejar secuelas y cicatrices ${ }^{64-66}$.

Se han propuesto otras modalidades de tratamiento para los casos de curso lento, como son los corticosteroides sistémicos, el interferón alfa-2a y los antibióticos sistémicos, así como la llamada "espera vigilante" 65 . Aunque en los linfomas cutáneos de células $\mathrm{B}$ de curso lento la supervivencia a los cinco años es mayor del $90 \%$, en los linfomas cutáneos de células $B$ grandes de las piernas varía entre 50 y $67 \%$, con recidivas en 30 a $60 \%$ de los casos, en su mayoría cutáneas. Sin embargo, en los linfomas cutáneos de células B de las piernas las tasas de recurrencia son más altas y hay tendencia a la diseminación extracutánea; por ello, es recomendable un seguimiento periódico ${ }^{22-24,64-66}$.

\section{CONCLUSIÓN}

La apoptosis participa en la patogénesis de los linfomas cutáneos y está comprometida en diferentes formas. La pérdida de la expresión del receptor Fas no es universal, pues en algunos casos permanece normal. Sin embargo, hay resistencia a la a apoptosis inducida por FasL como resultado de la sobreexpresión de inhibidores intracelulares de la apoptosis; también, se ha descrito la pérdida de la expresión de receptores de muerte. Por lo tanto, la desregulación de la apoptosis se debe, no sólo a la alteración de la expresión de receptores de muerte, sino también, a una inapropiada expresión de las moléculas intracelulares que participan en el control de este proceso. Los enfoques terapéuticos futuros deben apuntar a restaurar la expresión del receptor de la muerte, y se deben combinar con moduladores de las moléculas inhibidoras como el cFLIP y la estimulación de los demás mecanismos implicados en la apoptosis, lo que resulta en una vía terapéutica que beneficia a los pacientes con linfomas cutáneos.

\section{REFERENCIAS}

1. Willemze R, Hodak E, Zinzani PL, Specht L, Ladetto M. Primary cutaneous lymphomas: ESMO Clinical Practice Guidelines for diagnosis, treatment and follow-up. Ann Oncol. 2013;24:vi149-54.

2. Kim YH, Willemze R, Pimpinelli N, Whittaker S, Olsen $\mathrm{EA}$, Ranki A, et al. TNM classification system for primary cutaneous lymphomas other than mycosis fungoides and Sézary syndrome: A proposal of the International Society for Cutaneous Lymphomas (ISCL) and the Cutaneous Lymphoma Task Force of the European Organization of Research and Treatment of Cancer (EORTC). Blood. 2007;110:479-84.

3. Tchernev G, Cardoso JC, Arseniev L, Okamoto H. Extrinsic apoptotic pathways: A new potential "target" for more sufficient therapy in a case of cutaneous anaplastic large cd30+ alk-T-cell lymphoma. Indian J Dermatol. 2011;56:87-91.

4. Universidad de Valencia, España; 1997 Fecha de consulta: 14 de septiembre de 2013. Disponible en: http://www.uv.es/ derma/CLindex/CLlinfomas/CLlinfomas.htm.

5. Smith BD, Wilson LD. Cutaneous lymphoma. Curr Probl Cancer. 2008;32:43-87.

6. Willemze R, Jaffe ES, Burg G, Cerroni L, Berti E, Swerdlow SH, et al. WHO-EORTC classification for cutaneous lymphomas. Blood. 2005;105:3768-85.

7. Smith BD, Wilson LD. Cutaneous lymphomas. Semin Radiat Oncol. 2007;17:158-68.

8. Wilson LD, Hinds GA, Yu JB. Age, race, sex, stage, and incidence of cutaneous lymphoma. Clin Lymphoma Myeloma Leuk. 2012;12:291-6.

9. Hwang ST, Janik JE, Jaffe ES, Wilson WH. Mycosis fungoides and Sézary syndrome. Lancet. 2008;371:945-57. 
10. Deonizio JM, Guitart J. Current understanding of cutaneous lymphoma: Selected topics. Dermatol Clin. 2012;30:749-61, vii-viii.

11. Markova A, Weinstock MA. Trends in cutaneous lymphoma epidemiology. Clin Lymphoma Myeloma Leuk. 2010;10(Suppl.2):S63-S6.

12. Hinds GA, Heald P. Cutaneous T-cell lymphoma in skin of color. J Am Acad Dermatol. 2009;60:359-75.

13. Morales-Suárez-Varela MM, Olsen J, Johansen P, Kaerlev $\mathrm{L}$, Guenel P, Arveux P, et al. Occupational exposures and mycosis fungoides. A European multicentre case-control study (Europe). Cancer Causes Control. 2005;16:1253-9.

14. Herne KL, Talpur R, Breuer-McHam J, Champlin R, Duvic M. Cytomegalovirus seropositivity is significantly associated with mycosis fungoides and Sézary syndrome. Blood. 2003;101:2132-6.

15. Ballanger F, Bressollette C, Volteau C, Planche L, Dreno B. Cytomegalovirus: Its potential role in the development of cutaneous T-cell lymphoma. Exp Dermatol. 2009;18:574-6.

16. Gemmill R. Cutaneous T-cell lymphoma. Semin Oncol Nurs. 2006;22:90-6.

17. Pancake BA, Wassef EH, Zucker-Franklin D. Demonstration of antibodies to human T-cell lymphotropic virus-I tax in patients with the cutaneous T-cell lymphoma, mycosis fungoides, who are seronegative for antibodies to the structural proteins of the virus. Blood. 1996;88:3004-9.

18. Shohat M, Hodak E, Hannig H, Bodemer W, David M, Shohat B. Evidence for the cofactor role of human T-cell lymphotropic virus type 1 in mycosis fungoides and Sézary syndrome. $\mathrm{Br} \mathrm{J}$ Dermatol. 1999;141:44-9.

19. Gupta RK, Ramble J, Tong CY, Whittaker S, MacMahon E. Cytomegalovirus seroprevalence is not higher in patients with mycosis fungoides/Sézary syndrome. Blood. 2006;107:1241-2.

20. van Doorn R, Dijkman R, Vermeer MH, Starink TM, Willemze R, Tensen CP. A novel splice variant of the Fas gene in patients with cutaneous T-cell lymphoma. Cancer Res. 2002;62:5389-92.

21. Dereure O, Levi E, Vonderheid EC, Kadin ME. Infrequent Fas mutations but no Bax or p53 mutations in early mycosis fungoides: A possible mechanism for the accumulation of malignant $\mathrm{T}$ lymphocytes in the skin. J Invest Dermatol. 2002;118:949-56.

22. Gallardo FP, Ramón M. Diagnóstico y tratamiento de los linfomas cutáneos primarios de células B. Actas Dermosifiliogr. 2004;95:537-47.

23. García A, Estrach T. Una visión de los linfomas cutáneos primarios de células B. Medicina Cutánea Ibero-Latino-Americana. 2004;32:187-200.

24. Barragán ZF, Pulido N, Quintal MdJ, López MM. Linfoma cutáneo primario de células grandes B: informe de un caso. Dermatología Cosmética, Médica y Quirúrgica. 2013;11:213-6.

25. Zöchling N, Pütz B, Wolf p, Kerl H, Cerroni L. Human herpesvirus 8-specific DNA sequences in primary cutaneous B-cell lymphomas. Arch Dermatol. 1998;134:246-7.

26. Cho SG, Choi EJ. Apoptotic signaling pathways: Caspases and stress-activated protein kinases. J Biochem Mol Biol. 2002;35:24-7.

27. Kindt TJ, Goldsby RA, Osborne BA. Inmunología de Kuby. Sexta edición. México, D.F: McGraw Hill; 2007; 264-266
28. Stutz N, Johnson RD, Wood GS. The Fas apoptotic pathway in cutaneous T-cell lymphomas: Frequent expression of phenotypes associated with resistance to apoptosis. J Am Acad Dermatol. 2012;67:1327.e1-10.

29. Braun FK, Fecker LF, Schwarz C, Walden P, Assaf C, Durkop $\mathrm{H}$, et al. Blockade of death receptor-mediated pathways early in the signaling cascade coincides with distinct apoptosis resistance in cutaneous T-cell lymphoma cells. J Invest Dermatol. 2007;127:2425-37.

30. Abbas AK, Lichtman AH, Pillai S. Inmunología celular y molecular. $7^{\mathrm{a}}$ edición. Barcelona, España: Elseviere Saunders; 2012; 255-257.

31. Kaufmann SH, Hengartner MO. Programmed cell death Alive and well in the new millennium. Trends Cell Biol. 2001;11:526-34.

32. Haupt S, Berger M, Goldberg Z, Haupt Y. Apoptosis - the p53 network. J Cell Sci. 2003;116:4077-85.

33. Zhang CL, Kamarashev J, Qin JZ, Burg G, Dummer R, Dobbeling U. Expression of apoptosis regulators in cutaneous T-cell lymphoma (CTCL) cells. J Pathol. 2003;200:249-54.

34. Lamkanfi M, Dixit VM. Manipulation of host cell death pathways during microbial infections. Cell Host \& Microbe. 2010;8:44-54.

35. Amaral JD, Xavier JM, Steer CJ, Rodrigues CM. The role of p53 in apoptosis. Discov Med. 2010;9:145-52.

36. Manfe V, Biskup E, Johansen P, Kamstrup MR, Krejsgaard TF, Morling N, et al. MDM2 inhibitor nutlin-3a induces apoptosis and senescence in cutaneous T-cell lymphoma: Role of p53. J Invest Dermatol. 2012;132:1487-96.

37. Contassot E, French LE. Targeting apoptosis defects in cuta neous T-cell lymphoma. J Invest Dermatol. 2009;129:1059-61.

38. Wu J, Siddiqui J, Nihal M, Vonderheid EC, Wood GS. Structural alterations of the FAS gene in cutaneous T-cell lymphoma (CTCL). Arch Biochem Biophys. 2011;508:185-91.

39. Rieux-Laucat F, Le Deist F, Hivroz C, Roberts IA, Debatin KM, Fischer A, et al. Mutations in Fas associated with human lymphoproliferative syndrome and autoimmunity. Science. 1995;268:1347-9.

40. Contassot E, French LE. Epigenetic causes of apoptosis re sistance in cutaneous T-cell lymphomas. J Invest Dermatol. 2010;130:922-4.

41. Djerbi M, Screpanti V, Catrina AI, Bogen B, Biberfeld P, Grandien A. The inhibitor of death receptor signaling, FLICEinhibitory protein defines a new class of tumor progression factors. J Exp Med. 1999;190:1025-32.

42. Contassot E, Kerl K, Roques S, Shane R, Gaide O, Dupuis M, et al. Resistance to FasL and tumor necrosis factor-related apoptosis-inducing ligand-mediated apoptosis in Sézary syndrome T-cells associated with impaired death receptor and FLICE-inhibitory protein expression. Blood. 2008;111:4780-7.

43. Wozniak MB, Piris MA. Cutaneous T-cell lymphoma: Two faces of the same coin. J Invest Dermatol. 2010;130:348-51.

44. Dereure O, Portales P, Clot J, Guilhou JJ. Decreased expres sion of Fas (APO-1/CD95) on peripheral blood CD4+ T lymphocytes in cutaneous T-cell lymphomas. Br J Dermatol. 2000;143:1205-10.

45. Weshahy H, Mahgoub D, El-Eishy N, El-Tawdy AM, Bassiouny DA, Hunter N, et al. Bcl-2 expression in mycosis fungoides before and after PUVA therapy. Photodermatol Photoimmunol Photomed. 2010;26:107-9. 
46. Nevala H, Karenko L, Vakeva L, Ranki A. Proapoptotic and antiapoptotic markers in cutaneous T-cell lymphoma skin infiltrates and lymphomatoid papulosis. Br J Dermatol. 2001;145:928-37.

47. Wu J, Nihal M, Siddiqui J, Vonderheid EC, Wood GS. Low FAS/ CD95 expression by CTCL correlates with reduced sensitivity to apoptosis that can be restored by FAS upregulation. J Invest Dermatol. 2009;129:1165-73.

48. Zoi-Toli O, Vermeer MH, De Vries E, van Beek P, Meijer CJ, Willemze R. Expression of Fas and Fas-ligand in primary cutaneous T-cell lymphoma (CTCL): Association between lack of Fas expression and aggressive types of CTCL. Br J Dermatol. 2000;143:313-9.

49. Wu J, Wood GS. Reduction of Fas/CD95 promoter methylation, upregulation of Fas protein, and enhancement of sensitivity to apoptosis in cutaneous T-cell lymphoma. Arch Dermatol. 2011;147:443-9.

50. 50. Kelly-Sell MJ, Kim YH, Straus S, Benoit B, Harrison C, Sutherland $\mathrm{K}$, et al. The histone deacetylase inhibitor, romidepsin, suppresses cellular immune functions of cutaneous T-cell lymphoma patients. Am J Hematol. 2012;87:354-60.

51. Tiffon C, Adams J, van der Fits L, Wen S, Townsend P, Ganesan $\mathrm{A}$, et al. The histone deacetylase inhibitors vorinostat and romidepsin downmodulate IL-10 expression in cutaneous T-cell lymphoma cells. Br J Pharmacol. 2011;162:1590-602.

52. Jones CL, Wain EM, Chu CC, Tosi I, Foster R, McKenzie RC, et al. Downregulation of Fas gene expression in Sézary syndrome is associated with promoter hypermethylation. J Invest Dermatol. 2010;130:1116-25.

53. Lamprecht B, Kreher S, Mobs M, Sterry W, Dorken B, Janz M, et al. The tumour suppressor $\mathrm{p} 53$ is frequently nonfunctional in Sézary syndrome. Br J Dermatol. 2012;167:240-6.

54. Wang Y, Su M, Zhou LL, Tu P, Zhang X, Jiang X, et al. Deficiency of SATB1 expression in Sézary cells causes apoptosis resistance by regulating FasL/CD95L transcription. Blood. 2011;117:3826-35.

55. Grzanka A, Grzanka D, Gagat M, Tadrowski T, SokolowskaWojdylo M, Marszalek A, et al. Correlation of SATB1 expression with clinical course of cutaneous T-cell lymphomas. Pol J Pathol. 2012;63:101-5.

56. Sors A, Jean-Louis F, Pellet C, Laroche L, Dubertret L, Courtois G, et al. Down-regulating constitutive activation of the NF-kappaB canonical pathway overcomes the resistance of cutaneous T-cell lymphoma to apoptosis. Blood. 2006;107:2354-63.

57. Sors A, Jean-Louis F, Begue E, Parmentier L, Dubertret L, Dreano M, et al. Inhibition of IkappaB kinase subunit 2 in cutaneous T-cell lymphoma down-regulates nuclear factorkappaB constitutive activation, induces cell death, and potentiates the apoptotic response to antineoplastic chemotherapeutic agents. Clin Cancer Res. 2008;14:901-11.

58. Ferenczi K, Ohtola J, Aubert P, Kessler M, Sugiyama H, Somani AK, et al. Malignant T cells in cutaneous T-cell lymphoma lesions contain decreased levels of the antiapoptotic protein Ku70. Br J Dermatol. 2010;163:564-71.

59. Wollina U. Cutaneous T cell lymphoma: Update on treatment. Int J Dermatol. 2012;51:1019-36.

6o. Duhovic C, Child F, Wain EM. Management of cutaneous Tcell lymphoma. Clin Med. 2012;12:160-4.

61. Al-Yacoub N, Fecker LF, Mobs M, Plotz M, Braun FK, Sterry $\mathrm{W}$, et al. Apoptosis induction by SAHA in cutaneous T-cell lymphoma cells is related to downregulation of c-FLIP and enhanced TRAIL signaling. J Invest Dermatol. 2012;132:2263-74.
62. Zhang C, Li B, Gaikwad AS, Haridas V, Xu Z, Gutterman JU, et $a l$. Avicin D selectively induces apoptosis and downregulates p-STAT-3, bcl-2, and survivin in cutaneous T-cell lymphoma cells. J Invest Dermatol. 2008;128:2728-35.

63. Zhang C, Li B, Zhang X, Hazarika P, Aggarwal BB, Duvic M. Curcumin selectively induces apoptosis in cutaneous T-cell lymphoma cell lines and patients' PBMCs: Potential role for STAT-3 and NF-kappaB signaling. J Invest Dermatol. 2010;130:2110-9.

64. Fink-Puches R, Wolf $\mathrm{IH}$, Zalaudek I, Kerl H, Cerroni L. Treatment of primary cutaneous B-cell lymphoma with rituximab. J Am Acad Dermatol. 2005;52:847-53.

65. Fernández-Guarino M, Ortiz-Romero PL, Fernández-Misa $\mathrm{R}$, Montalbán C. Rituximab in the treatment of primary cutaneous B-cell lymphoma: A review. Actas Dermosifiliogr. 2014;105:438-45.

66. Morales AV, Advani R, Horwitz SM, Riaz N, Reddy S, Hoppe $\mathrm{RT}$, et al. Indolent primary cutaneous B-cell lymphoma: Experience using systemic rituximab. J Am Acad Dermatol. 2008;59:953-7. 